\title{
Pengaruh Model Pendidikan Montessori terhadap Hasil Belajar Matematika pada Siswa Kelas II SD Muhammadiyah 3 Parepare
}

\author{
Asrinan 1*, Asdar Dollo $^{1}$ \\ 1. Universitas Muhammadiyah Parepare \\ e-mail: asrinan.044@gmail.com
}

(Received: 26-09-2021; Reviewed: 29-09-2021; Accepted: 06-10-2021)

\begin{abstract}
Abstrak
Penelitian ini bertujuan untuk mendeskripsikan pengaruh model pendidikan Montessori terhadap hasil belajar matematika pada siswa kelas II SD Muhammadiyah Parepare pada semester genap tahun ajaran 2020/2021. Penelitian ini merupakan penelitian kuantitatif dengan menggunakan metode quasi eksperimen. Data-data dikumpulkan oleh peneliti melalui pemberian tes kepada siswa. Hasil penelitian menunjukkan bahwa model pendidikan Montessori memberikan dampak positif terhadap hasil belajar matematika siswa. Berdasarkan perhitungan uji hipotesis menggunakan uji Independent Sample T Test, diperoleh nilai signifikansi sebesar 0,000. Berdasarkan kriteria pengujian, karena nilai signifikansi lebih kecil dari 0,05 sehingga dapat disimpulkan bahwa ada perbedaan yang signifikan antara hasil belajar siswa yang menggunakan metode Montessori dengan metode konvensional. Perbedaan tersebut disebabkan karena perbedaan perlakuan selama proses pembelajaran berlangsung.
\end{abstract}

Kata Kunci: Hasil Belajar, Konvensional, Matematika, Montessori

\section{Abstract}

This research aimed to describe the influence of the Montessori education model on the math learning achievement of the second-grade students of SD Muhammadiyah Parepare academic year of 2020/2021. The quantitative research was applied with the Quasi-Experimental method. The data were collected through the tests. The result of the research showed the Montessori education model gave a positive impact on the students' achievement. Based on T-Test independent sample testing, the significant result was 0,000. Based on the testing criteria, it can be concluded that there was a difference significant between the students' learning achievement that uses the Montessori education model and the conventional method because the significant result was less than 0,05. It was caused by the difference in the treatment during the learning process.

Keywords: conventional, learning achievement, mathematics, Montessori

\section{PENDAHULUAN}

Pendidikan bagi kehidupan manusia merupakan kebutuhan mutlak yang harus dipenuhi sepanjang hayat (Fuad, 2003: 2). Menurut UNESCO pendidikan hendaknya dibangun dengan empat pilar, yaitu learning to know, learning to do, learning to be, dan learning to live together. Hal ini menunjukkan tentang betapa pentingnya pendidikan bagi kehidupan manusia. Anak sebagai makhluk individu dan sosial sangat berhak untuk mendapatkan pendidikan yang sesuai dengan kebutuhan dan kemampuannya. Pendidikan diberikan kepada seorang anak dengan harapan anak 
dapat tumbuh dan berkembang secara cerdas sesuai dengan potensi yang dimilikinya, supaya kelak dapat menjadi anak bangsa yang berkualitas (Suyadi, 2011: 7).

Kualitas pendidikan di Indonesia dipengaruhi oleh proses pembelajaran yang terjadi di sekolah, baik dari sekolah dasar hingga menengah. Pembelajaran yang baik akan menghasilkan kualitas siswa yang baik dari sisi hasil belajar maupun perkembangan sosial pribadi siswa. Untuk mendapatkan standar pendidikan dengan kualitas yang baik, maka diperlukan model-model pembelajaran yang sesuai dengan lingkungan dimana model itu akan di implementasikan.

Salah satu masalah pokok dalam pembelajaran pada pendidikan formal atau sekolah dewasa ini adalah masih rendahnya daya serap peserta didik. Hal ini nampak pada hasil belajar peserta didik yang senantiasa masih sangat memprihatinkan. Prestasi ini merupakan hasil kondisi pembelajaran yang masih bersifat konvensional dan tidak menyentuh ranah dimensi peserta didik itu sendiri. Pada pembelajaran ini suasana kelas cenderung teacher-centered sehingga siswa menjadi pasif.

Matematika adalah mata pelajaran yang diajarkan di jenjang pendidikan dasar hingga menengah dan merupakan ilmu dengan objek abstrak dengan pengembangan melalui penalaran deduktif telah mampu mengembangkan model- model yang merupakan contoh dari sistem itu yang pada akhirnya telah digunakan untuk memecahkan persoalan dalam kehidupan sehari-hari. Matematika juga dapat mengubah pola pikir seseorang menjadi pola pikir yang matematis, sistematis, logis, kritis dan cermat.

Tetapi sistem ini tidak sejalan dengan tahap perkembangan mental anak, sehingga yang dianggap logis dan jelas oleh orang dewasa pada matematika, masih merupakan hal yang tidak masuk akal dan menyulitkan bagi anak. Padahal matematika bertujuan untuk medidik siswa agar berpikir logis dan memiliki kemampuan nalar yang tinggi. Menurut Piaget anak usia 7-12 tahun masih berpikir pada tahap operasi konkrit artinya mereka belum bisa berpikir secara formal. Ciri-ciri anak pada tahap ini hanya dapat memahami operasi logis dengan bantuan benda-benda konkrit, mereka belum dapat berpikir deduktif, berpikir transitif. Padahal matematika adalah ilmu deduktif, formal, hirarki dan menggunakan bahasa symbol yang memiliki arti yang padat. Karena adanya perbedaan karakteristik antara matematika dan anak usia 7-12 tahun, maka akan sulit dipahami oleh mereka jika tidak diajarkan tanpa memperhatikan tahap berpikir sesuai usia mereka.

Melihat fenomena tersebut serta begitu pentingnya perkembangan seorang anak, maka seorang tokoh pendidikan bernama Maria Montessori berpendapat jika anak diberi materi dan lingkungan yang tepat, anak cenderung bisa mengerjakan aktifitas secara spontan. Lewat aktifitas, anak mendapat pengetahuan dan keterampilan. Anak akan belajar sesuai keinginan pribadi dan mengatasi ketidakmampuan tanpa bantuan dan campur tangan orang tua.

Pendidikan Montessori membantu anak memuaskan dan memenuhi keinginan sekaligus menunjang perkembangan total. Ini berarti memberikan setiap aspek pertumbuhan seperti fisik, intelektual, linguistik, emosi, spiritual, atau sosial, yang proporsional setiap saat agar membantu anak berkembang menjadi manusia utuh. Montessori berpendapat manusia kreatif sangat haus ilmu dari berbagai disiplin ilmu. 


\section{Metode}

Penelitian ini merupakan penelitian kuantitatif dengan menggunakan metode quasi eksperimen yaitu metode yang tidak memungkinkan bagi peneliti melakukan pengontrolan secara penuh terhadap variabel dan kondisi eksperimen. Pelaksanaannya melibatkan dua kelompok yaitu kelompok eksperimen yang diberikan perlakuan dengan pendekatan Montessori dan kelompok kontrol yang diberikan pendekatan pembelajaran konvensional, dengan desain penelitian seperti pada tabel 1 .

\section{Tabel 1. Desain Penelitian}

\begin{tabular}{ccccc}
\hline & Grup & Pre test & Treatmen & Post test \\
\hline $\mathrm{R}$ & Eksperimen & $\mathrm{T} 1$ & $\mathrm{X}$ & $\mathrm{T} 2$ \\
$\mathrm{R}$ & Kontrol & $\mathrm{T} 1$ & $\mathrm{X}$ & $\mathrm{T} 2$ \\
\hline
\end{tabular}

Keterangan:

T1 : Pre test

T2 : Post test

$\mathrm{X}_{\mathrm{E}} \quad$ : Perlakuan dengan Model Pembelajaran Pendidikan Montessori

$\mathrm{X}_{\mathrm{K}} \quad$ : Perlakuan dengan Model Pembelajaran Konvensional

(Sukardi, 2005: 185)

\section{A. Tempat dan Waktu}

Penelitian ini dilaksanakan pada semester genap tahun ajaran 2020/2021 kelas II SD Muhammadiyah 3 Parepare.

\section{B. Populasi}

Populasi dalam penelitian ini adalah siswa kelas II SD Muhammadiyah 3 Parepare, dimana sekaligus sebagai sampel penelitian, karena hanya terdapat dua kelas saja yaitu kelas IIA dan IIB, dengan rata-rata sebanyak 20 siswa setiap kelas.

\section{Pembahasan}

\section{Analisis Deskriptif}

\section{a. Deskriptif Hasil Belajar Matematika Kelas Eksperimen}

Perhitungan analisis deskriptif dari tes awal (pre-test) dan tes akhir (post- test) kelas eksperimen menggunakan IBM SPSS Statistics 20, seperti pada tabel 2.

\section{Tabel 2 Deskriptif Hasil Belajar Matematika Kelas Eksperimen}




\begin{tabular}{|c|c|c|c|c|}
\hline \multicolumn{5}{|c|}{ Statistics } \\
\hline & & PRETEST & POSTEST & PROGRESS \\
\hline \multirow[t]{2}{*}{$\mathrm{N}$} & Valid & 20 & 20 & 20 \\
\hline & Missing & 0 & 0 & 0 \\
\hline Mean & & 53,50 & 81,10 & 27,60 \\
\hline Median & & 50,00 & 81,00 & 23,50 \\
\hline Mode & & 50 & $60^{\mathrm{a}}$ & $15^{\mathrm{a}}$ \\
\hline Std. Deviation & & 16,631 & 13,139 & 14,416 \\
\hline Variance & & 276,579 & 172,621 & 207,832 \\
\hline Skewness & &,- 089 &,- 286 & 1,526 \\
\hline \multicolumn{5}{|c|}{ Std. Error of Skewness } \\
\hline & &, 512 &, 512 &, 512 \\
\hline Range & & 60 & 40 & 60 \\
\hline Minimum & & 20 & 60 & 10 \\
\hline Maximum & & 80 & 100 & 70 \\
\hline Sum & & 1070 & 1622 & 552 \\
\hline
\end{tabular}

Berdasarkan hasil analisis pada tabel 2 diperoleh: (1) rata-rata data tes awal untuk hasil belajar matematika kelas eksperimen sebesar 53,50 dengan simpangan baku sebesar 16,631, median sebesar 50,00, modus sebesar 50, nilai maksimum sebesar 80 dan nilai minimum sebesar 20; (2) rata-rata data tes akhir untuk hasil belajar matematika kelompok eksperimen sebesar 81,10 dengan simpangan baku sebesar 13,139, median sebasar 81,00, modus sebesar 60 , nilai maksimum sebesar 100 dan nilai minimum sebesar 60; dan (3) rata-rata peningkatan hasil belajar matematika kelas eksperimen sebesar 27,60 dengan simpangan baku sebesar 14,416, median sebesar 23,50, modus sebesar 15, nilai maksimum sebesar 70 dan nilai minmum sebesar 10 .

\section{b. Deskriptif Hasil Belajar Matematika Kelas Kontrol}

Perhitungan analisis deskriptif dari tes awal (pre-test) dan tes akhir (post-test) kelas kontrol menggunakan IBM SPSS Statistics 20, seperti pada tabel 3.

Tabel 3 Deskriptif Hasil Belajar Matematika Kelas Kontrol

\begin{tabular}{lrrrr}
\hline \multicolumn{5}{c}{ Statistics } \\
\hline & & PRETEST & POSTEST & PROGRESS \\
\hline $\mathrm{N}$ & Valid & 20 & 20 & 20 \\
& Missing & 0 & 0 & 0 \\
Mean & & 44,25 & 58,75 & 14,50 \\
Median & & 45,00 & 60,00 & 10,00
\end{tabular}




\begin{tabular}{lrrr} 
Mode & $20^{\mathrm{a}}$ & 70 & 10 \\
Std. Deviation & 16,958 & 15,717 & 11,110 \\
Variance & 287,566 & 247,039 & 123,421 \\
Skewness &,- 091 &,- 105 & 2,059 \\
Std. Error of & & & \\
Skewness &, 512 &, 512 &, 512 \\
Range & 50 & 45 & 45 \\
Minimum & 20 & 35 & 5 \\
Maximum & 70 & 80 & 50 \\
Sum & 885 & 1175 & 290 \\
\hline
\end{tabular}

Berdasarkan hasil analisis pada tabel 3 diperoleh: (1) rata-rata data tes awal untuk hasil belajar matematika kelas kontrol sebesar 44,25 dengan simpangan baku sebesar 16,958, median sebasar 45,00, modus sebesar 20, nilai maksimum sebesar 70 dan nilai minimum sebesar 20; dan (2) rata-rata data tes akhir untuk hasil belajar matematika kelas kontrol sebesar 58,75 dengan simpangan baku sebesar 15,717, median sebesar 60, modus sebesar 70, nilai maksimum sebesar 80 dan nilai minimum sebesar 35; dan (3) rata-rata peningkatan hasil belajar matematika kelas kontrol sebesar 14,50 dengan simpangan baku sebesar 11,110, median sebesar 10,00, modus sebesar 10, nilai maksimum sebesar 50 dan nilai minimum sebesar 5 .

\section{Analisis Inferensial}

\section{a. Uji Normalitas}

Data yang digunakan untuk uji normalitas adalah peningkatan (Progress) hasil belajar matematika kelas eksperimen dan kelas kontrol. Secara teknik peneliti menggunakan bantuan program IBM SPSS Statistics 20 untuk mengetahui normalitas data yang hasilnya dapat dilihat pada tabel 4 .

Tabel 4 Uji Normalitas Progress Hasil Belajar Matematika Siswa

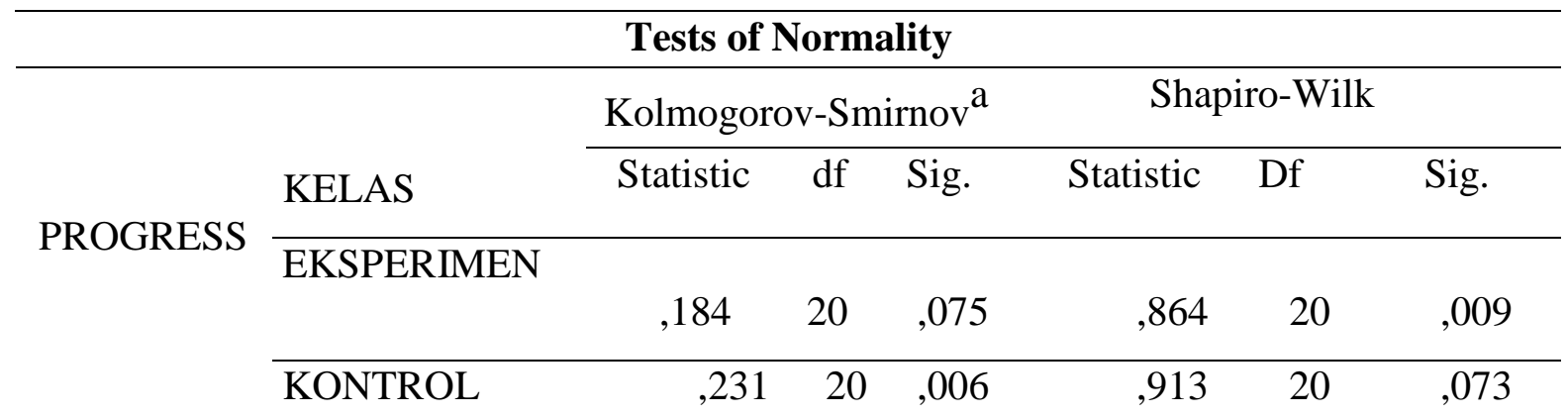


Berdasarkan hasil output uji normalitas varians dengan menggunakan uji KolmogorovSmirniv, nilai signifikansi peningkatan hasil belajar untuk kelas eksperimen adalah 0,075 dan kelas kontrol adalah 0,006. Karena nilai signifikansi kedua kelas tersebut lebih besar dari $\alpha(0,05)$, maka dapat disimpulkan bahwa data peningkatan hasil belajar matematika siswa berdistribusi normal.

\section{b. Uji Homogenitas}

Setelah kedua kelompok sampel penelitian dinyatakan berdistribusi normal, selanjutnya dicari nilai homogenitasnya. Data yang digunakan untuk uji normalitas adalah peningkatan (Progress) hasil belajar matematika kelas eksperimen dan kelas kontrol. Secara teknik peneliti menggunakan bantuan program IBM SPSS Statistics 20 untuk mengetahui homogenitas data yang hasilnya dapat dilihat pada tabel 5 .

Tabel 5 Uji Homogenitas Progress Hasil Belajar Matematika Siswa

\begin{tabular}{lllllll}
\hline \multicolumn{5}{c}{ Test of Homogeneity of Variance } & & \\
\hline & & $\begin{array}{c}\text { Levene } \\
\text { Statistic }\end{array}$ & & & \\
& & df1 & df2 & Sig. \\
\hline PROGRESS & Based on Mean & 2,201 & 1 & 38 &, 146 \\
& $\begin{array}{l}\text { Based on Median } \\
\text { Based on Median and } \\
\text { with adjusted df }\end{array}$ & 1,942 & 1 & 38 &, 172 \\
& $\begin{array}{l}\text { Based on trimmed } \\
\text { mean }\end{array}$ & 1,942 & 1 & 32,173 &, 173 \\
& & 1,987 & 1 & 38 &, 167 \\
\hline
\end{tabular}

Berdasarkan hasil output uji homogenitas varians bahwa nilai signifikansi sebesar 0,146. Karena nilai sig > 0,05 maka dapat disimpulkan bahwa kedua sampel bersifat homogen (varians sama).

\section{c. Uji Hipotesis}

Setelah dilakukan uji prasyarat analisis ternyata diperoleh kedua kelas berdistribusi normal dan homogen. Langkah selanjutnya adalah pengujian hipotesis dengan menggunakan uji-t. Hasil uji hipotesis menggunakan program IBM SPSS 20 seperti pada tabel 6.

Tabel 6 Uji Hipotesis

\begin{tabular}{lllrrr}
\hline \multicolumn{5}{c}{ Group Statistics } \\
\hline \multirow{2}{*}{ PROGRESS } \\
\cline { 2 - 6 } & KELAS & $\mathrm{N}$ & Mean & Std. Deviation & Std. Error Mean \\
\cline { 2 - 6 } & EKSPERIMEN & 20 & 27,60 & 14,416 & 3,224 \\
& KONTROL & 20 & 13,00 & 8,944 & 2,000 \\
\hline
\end{tabular}




\begin{tabular}{|c|c|c|c|c|c|c|}
\hline & & $\begin{array}{l}\text { Lever } \\
\text { for } \mathrm{Eq} \\
\mathrm{Var}\end{array}$ & $\begin{array}{l}\text { Test } \\
\text { lity of } \\
\text { ces }\end{array}$ & t-test fo & Equality & of Means \\
\hline & & $\mathrm{F}$ & Sig. & $\mathrm{T}$ & Df & Sig. (2- tailed) \\
\hline PROGRESS & $\begin{array}{l}\text { Equal } \\
\text { variances } \\
\text { assumed }\end{array}$ & 2,201 & , 146 & 3,849 & 38 & ,000 \\
\hline & $\begin{array}{l}\text { Equal } \\
\text { variances not } \\
\text { assumed }\end{array}$ & & & 3,849 & 31,740 & ,001 \\
\hline
\end{tabular}

Berdasarkan hasil uji-t nilai progress diperoleh nilai signifikansi 0,000, ini lebih kecil dari 0,05 sehingga $\mathrm{H} 0$ ditolak dan $\mathrm{H} 1$ diterima. Artinya bahwa ada perbedaan yang signifikan antara hasil belajar siswa yang menggunakan metode Montessori dengan metode Konvensional. Hasil penelitian menunjukkan bahwa dalam pembelajaran matematika dengan menggunakan model pendidikan Montessori lebih efektif dari pada pembelajaran konvensional di SD Muhammadiyah 3 Parepare. Hasil penelitian ini sejalan dengan penelitian yang dilakukan oleh Cipta (2018) menunjukkan penanaman konsep matematika dengan menggunakan pembelajaran motessori adalah siswa dapat menggunakan matematika berdasarkan penalaran, bukan berdasarkan berhitung tanpa logika. Penelitian Maranta (2019) juga menghasilkan bahwa prosedur penelitian dan pengembangan alat peraga pengenalan bilangan bulat positif dan negative mata pelajaran matematika menggunakan langkah ADDIE yaitu Analyze, Design, Development, Implentation dan Evaluate sebagai langkah penelitian dan pengembangan dan memiliki ciri-ciri antara lain: menarik, bergradasi, autocorrection, auto-education, dan kontekstual sesuai dengan ciri-ciri metode Montessori. Berdasarkan hasil penelitian Mellawaty (2019) menunjukkan bahwa langkah-langkah Model Montessori dapat digunakan pada pelajaran matematika untuk menjelaskan materi perkalian.

Berdasarkan hasil analisis deskriptif diperoleh gambaran hasil belajar matematika siswa yang diajar menggunakan model pendidikan Montessori terjadi peningkatan nilai rata-rata sebesar 27,60. Ini berarti hasil belajar matematika siswa yang diajar dengan menggunakan model pendidikan Montessori lebih baik dari hasil belajar matematika siswa yang diajar dengan pembelajaran konvensional dengan peningkatan nilai rata-rata sebesar 14,50. Hasil uji-t nilai progress diperoleh nilai signifikansi 0,000, ini lebih kecil dari 0,05 sehingga H0 ditolak dan $\mathrm{H} 1$ diterima. Hal ini berarti model pendidikan Montessori lebih efektif daripada pembelajaran konvensional terhadap hasil belajar matematika siswa.

Berdasarkan hasil analisis tersebut dapat dijelaskan bahwa siswa yang belajar dengan menggunakan model pendidikan montessori lebih merespon materi yang diajarkan oleh guru, siswa akan lebih berpartisipasi pula dalam kegiatan belajar mengajar dengan model pendidikan Montessori sehingga nilai yang diperoleh lebih baik. 


\section{Kesimpulan}

Berdasarkan hasil penelitian yang dilakukan mengenai pengaruh model pendidikan Montessori terhadap hasil belajar matematika siswa, bahwa model pendidikan Montessori terhadap hasil belajar matematika siswa memberikan dampak positif terhadap hasil belajar siswa. Berdasarkan perhitungan uji hipotesis menggunakan uji Independent Sample T Test, diperoleh nilai signifikansi sebesar 0,000. Berdasarkan kriteria pengujian, karena nilai signifikansi lebih kecil dari 0,05 sehingga dapat disimpulkan bahwa ada perbedaan yang signifikan antara hasil belajar siswa yang menggunakan metode Montessori dengan metode konvensional. Perbedaan tersebut disebabkan karena perbedaan perlakuan selama proses pembelajaran berlangsung. Jadi, dengan kata lain pembelajaran dengan model pendidikan Montessori mempunyai pengaruh terhadap hasil belajar matematika siswa.

Pembelajaran dengan menggunakan model pendidikan Montessori dapat dijadikan alternatif variasi dalam model pembelajaran, khususnya dalam upaya untuk meningkatkan hasil belajar. Sehingga dapat menjadi salah satu solusi dari sekian banyak permasalahan kualitas pendidikan di Indonesia, khususnya dalam pendidikan matematika.

\section{Referensi}

Aisyah, L.S. (2019) Integrasi model montessori pada siswa tunagrahita ringan: eksplorasi, desain dan implementasi dalam materi perkalian. Mathline. 4(2), 139-147. doi: https://doi.org/10.31943/mathline.v4i2.114.

Citra, D.A.S. (2018) Penerapan pendekatan montessori untuk menanamkan konsep bilangan cacah pada siswa tk putera zaman malang. Jurnal Matematika dan Pembelajaran. 30-34. Diperoleh dari 293564-penerapan-pendekatan-montessori-untuk-me-e035dd5d.pdf (neliti.com).

Fuad, I. (2003). Dasar-dasar Pendidikan. Jakarta: PT Rineka Cipta.

Maranta, P.F. (2010). Pengembangan alat praga berbasis montessori spindle box pada mata pelajaran matematika kelas III sd materi bilangan. (Skripsi). Diperoleh dari 151134069_full.pdf (usd.ac.id).

Montessori, M. (2013). Metode Montessori: Panduan Wajib untuk Guru dan Orangtua Didik PAUD (Pendidikan Anak Usia Dini). Yogyakarta: Pustaka Pelajar.

Piaget, J. (2002). Tingkat Perkembangan Kognitif. Jakarta: Gramedia.

Sukardi (2005). Metodologi Penilitian Pendidikan Kompetensi dan Praktiknya. Jakarta: Bumi Aksara.

Suyadi. (2011). Panduan Penelitian Tindakan Kelas Buku Panduan Wajib bagi Para Pendidik. Yogyakarta: DIVA Press. 